\title{
Study on the wear and damage behaviors of hypereutectoid rail steel in low temperature environment
}

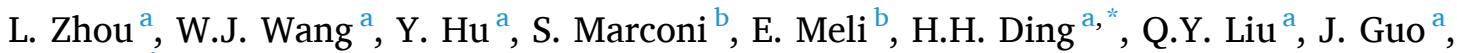 \\ A. Rindi ${ }^{b}$

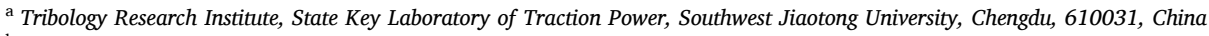 \\ ${ }^{\mathrm{b}}$ Department of Industrial Engineering, University of Florence, Firenze, 50139, Italy
}

\section{A R T I C L E I N F O}

\section{Keywords:}

Wheel/rail wear

Wheel/rail damage

Low temperature

Third body layer

Hypereutectoid rail steel

Eutectoid rail steel

\begin{abstract}
A B S T R A C T
In this study, the wear and damage behaviors of three heavy haul rail steels (including one hypereutectoid rail steel and two eutectoid rail steels) were investigated at room (around $20^{\circ} \mathrm{C}$ ) and low $\left(-40^{\circ} \mathrm{C}\right)$ temperatures using a rolling-sliding wear test machine. The results indicated that, compared with eutectoid steels, the hypereutectoid rail steel had a better wear resistance and a better rolling contact fatigue (RCF) resistance at the room temperature, and better wear resistance but worse RCF resistance at the low temperature. Compared with the room temperature, at the low temperature both the hypereutectoid and eutectoid rails had better wear resistance, the RCF resistance of eutectoid steels was improved but the RCF resistance of hypereutectoid rail was reduced. At the room temperature, the worn surfaces of both wheel and rail materials were dominated by surface cracks. On the contrary, at the low temperature, the worn surfaces of wheel and rail materials were dominated by third body layers (TBLs) and oxidized spots, respectively.
\end{abstract}

\section{Introduction}

The tribological properties of the wheel/rail materials are affected by many factors, such as the axles load, hardness matching, surface roughness, humidity, contaminants, etc. [1-4]. In addition to these factors, the wheel/rail interface also faces the extreme low temperature environment in winter, especially in the high altitude and northern areas. The extreme low temperature could reach $-46{ }^{\circ} \mathrm{C}$ in the north part of China [5]. The low temperature is a great challenge to the service safety of the wheel and rail. The mechanical properties of steels deteriorate significantly at the low temperatures, which increases the risk of damage and failure of wheel and rail materials [6-8]. According to the field investigation, $60 \%$ of the rail broken accidents occurred in winter $[9,10]$. Therefore, it is necessary to study the service behaviors of wheel/rail materials in the low temperature environment.

Under low temperature conditions, wheel/rail materials are required with high impact energies and low ductile brittle transition temperatures (DBTT) [11]. In previous works [5,12,13], a series of experiments were carried out to investigate the impact toughness and fatigue life of wheel and rail materials at low temperatures. The results showed that the DBTT of U71Mn rail steel approached $-10^{\circ} \mathrm{C}$, which was higher than the usual temperature in the high altitude and northern areas. At same time, in other works [14-16], the mechanical properties of rails at low temperature were improved through adding alloying elements. The decrease in ambient temperature could not only lead to the deterioration of wheel and rail materials, but also change the atmosphere around the wheel/rail interface. An obvious instance was that the change in humidity could influence the type and content of iron oxide [3], and influence the tribology behavior of wheel/rail materials.

In recent years, Lyu et al. [17], Zhu et al. [18], Ma et al. [19,20] and Shi et al. [21] studied the friction, wear and damage behaviors of wheel and rail materials at low temperatures. However, because of the differences in test rigs and materials considered in the tests, the influence of low temperature (lower than $-35{ }^{\circ} \mathrm{C}$ ) on wear may be different [22]. Wear was milder at $-35{ }^{\circ} \mathrm{C}$ than at the room temperature in Ref. [17] but the wear rate was larger at $-40^{\circ} \mathrm{C}$ than at the room temperature in Ref. [19].

In recent years, the axle load of the trains has been gradually increased to improve the capacity of railway, and the maximum axle load has reached 40 t. Under such a high contact stress condition, the traditional heavy-haul rail steels are facing the failure of severe wear and damage [23,24]. Generally, the wear resistance of materials

\footnotetext{
* Corresponding author.

E-mail address: haohao.ding@swjtu.edu.cn (H.H. Ding).
} 


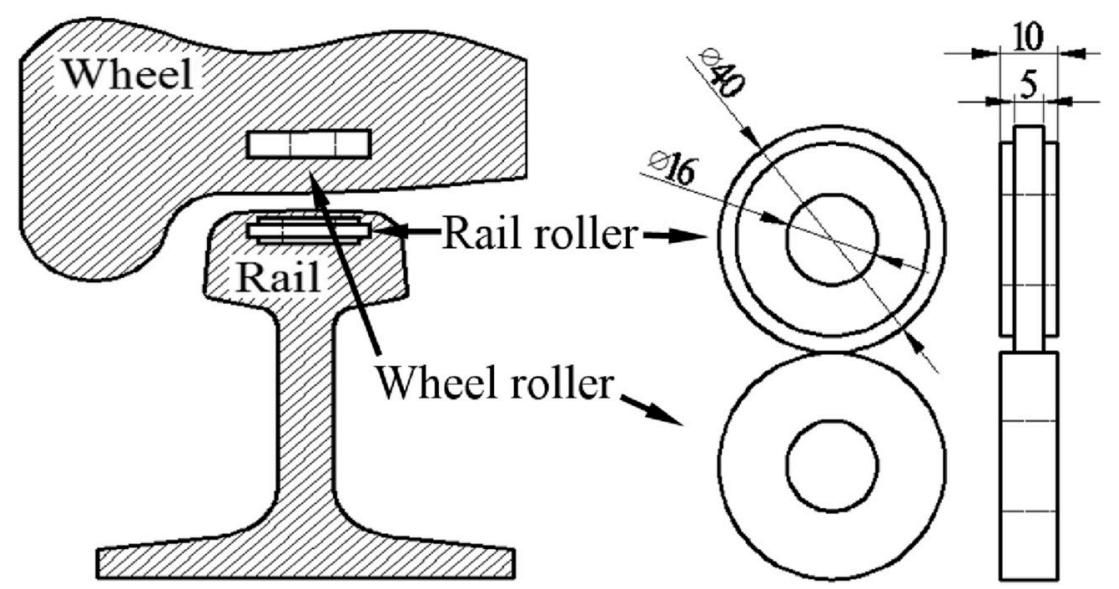

Fig. 1. Sampling positions and dimensions of wheel and rail rollers.

Table 1

Chemical compositions of rail and wheel materials (wt\%).

\begin{tabular}{|c|c|c|c|c|c|c|c|}
\hline & $\mathrm{C}$ & Mn & $\mathrm{Si}$ & $\mathrm{Cr}$ & $\mathrm{V}$ & $\mathrm{P}$ & $S$ \\
\hline Rail 1\# & $0.71-0.80$ & $0.50-0.70$ & $0.70-1.05$ & $\leq 0.20$ & $0.04-0.08$ & $\leq 0.03$ & $\leq 0.03$ \\
\hline Rail 2\# & $0.75-0.82$ & $0.50-0.83$ & $0.70-1.05$ & $0.30-0.50$ & $0.07-0.10$ & $\leq 0.025$ & $\leq 0.025$ \\
\hline Rail 3\# & $0.90-0.95$ & 0.94-1.02 & $0.48-0.52$ & $0.22-0.23$ & $0.06-0.10$ & $0.01-0.014$ & $0.04-0.07$ \\
\hline Wheel & $0.67-0.77$ & $0.60-0.90$ & $0.15-1.0$ & $\leq 0.25$ & $\leq 0.04$ & $\leq 0.030$ & $0.005-0.04$ \\
\hline
\end{tabular}

Table 2

Mechanical properties of rail and wheel materials.

\begin{tabular}{llll}
\hline Materials & Tensile strength $\delta_{\mathrm{b}} / \mathrm{MPa}$ & Elongation rate $\Delta / \%$ & Hardness $\mathrm{HV}_{0.5}$ \\
\hline Rail 1\# & $\geq 1180$ & $\geq 10$ & $367 \pm 19$ \\
Rail 2\# & $\geq 1280$ & $\geq 10$ & $390 \pm 18$ \\
Rail 3\# & $\geq 1300$ & $\geq 8$ & $423 \pm 13$ \\
Wheel & $\geq 1170$ & $\geq 16$ & $357 \pm 9$ \\
\hline
\end{tabular}

increases with the increase in hardness. Consequently, it is necessary to develop new rail steels with higher strength to meet the current railway demands. However, with the development of traditional eutectoid rail steels, the space for promoting the strength limit of eutectoid rail steels is getting smaller. Therefore, researchers are developing hypereutectoid steels with higher strengths $[25,26]$. The hypereutectoid steels have a large content of cementite. Cementite acts as a good obstacle for dislocation during the crystal deformation, thus improves the strength of steel. Several hypereutectoid steel rails have been developed [27-29]. In 1997, Masaharu [27] suggested the application of hypereutectoid steel to heavy haul track rail. Recently, Takahashi [28] checked the micro-structure of hypereutectoid rail steel under the rolling-sliding condition. The pearlite structure in hypereutectoid rail showed a good resistance to plastic deformation.

Under the low temperature condition, the ductility of wheel/rail materials decreases sharply. So the fatigue of wheel and rail becomes more significant, which affects the service safety. Meanwhile, due to the high carbon content, the plasticity of hypereutectoid rail steel decreases. Hypereutectoid steels exhibit good wear resistance at room temperature, but the wear and damage behaviors at low temperatures have not been reported yet. In this study, the wear and damage behaviors of three heavy haul rail steels (including one hypereutectoid rail steel and two eutectoid rail steels) were investigated at room (around $20^{\circ} \mathrm{C}$ ) and low $\left(-40{ }^{\circ} \mathrm{C}\right)$ temperatures using a rolling-sliding wear test machine. The friction, wear and damage of rail materials were analyzed. After the test, the third body layer (TBL) was observed at the wheel and rail interface. The formation mechanism and the effect of TBL on tribological behaviors of wheel and rail materials were also discussed in detail.

\section{Experimental details}

\subsection{Materials and samples}

In this study, three heavy haul rail materials with different carbon contents were selected to roll and slide against the wheel material. The sampling positions and dimensions are shown in Fig. 1. The wheel and rail rollers were taken from the railhead and wheel tread, respectively, as shown in Fig. 1(a). The diameter of wheel and rail rollers is $40 \mathrm{~mm}$ and the contact width is $5 \mathrm{~mm}$, as shown in Fig. 1(b). The chemical compositions (wt \%) and mechanical properties of the three kinds of rails and the wheel materials are shown in Table 1 and Table 2, respectively. It can be seen from Table 1 that the carbon contents of the rail 1 \# and rail $2 \#$ are near $0.77 \%$, which means that rail $1 \#$ and rail $2 \#$ are eutectoid steels. The carbon content of rail $3 \#$ is in the range of $0.90-0.95 \%$, which means that rail 3 \# belongs to the typical hypereutectoid steel. By controlling the heat treatment process, a part of carbon atoms enters the pearlite lamellar structure, so the cementite density in rail $3 \#$ is larger than those in rail $1 \#$ and rail $2 \#$. The interlamellar spacings of pearlite in the three kinds of rails are around $178 \mathrm{~nm}, 158 \mathrm{~nm}$ and $93 \mathrm{~nm}$, respectively. Both the strength and hardness of rail $3 \#$ are higher than those of rail $1 \#$ and rail 2\# (Table 2). In general, with the increase in carbon content, the plasticity and toughness decrease. Thus, the elongation ratio of rail $3 \#(8 \%)$ is lower than those of rail $1 \#$ and rail $2 \#(10 \%)$. Fig. 2 shows the microstructures of rails and wheel materials. Rail $1 \#$ and rail $2 \#$ only contain the pearlite phase. In rail 3\#, beyond the pearlite phase, a little secondary cementite can be observed around the pre-austenite grain boundary. The wheel sample contains both pearlite and ferrite phases.

\subsection{Experimental apparatus and processes}

The experiment was conducted on a rolling-sliding wear test machine with a cooling system which could provide the lowest temperature of $-60{ }^{\circ} \mathrm{C}$. The diagram of the test machine is presented in Fig. 3. This rolling-sliding testing machine consists of a mechanical unit, an electric control unit and an information collecting unit. The rail and wheel rollers were fixed on the upper and lower shafts, respectively. The upper 


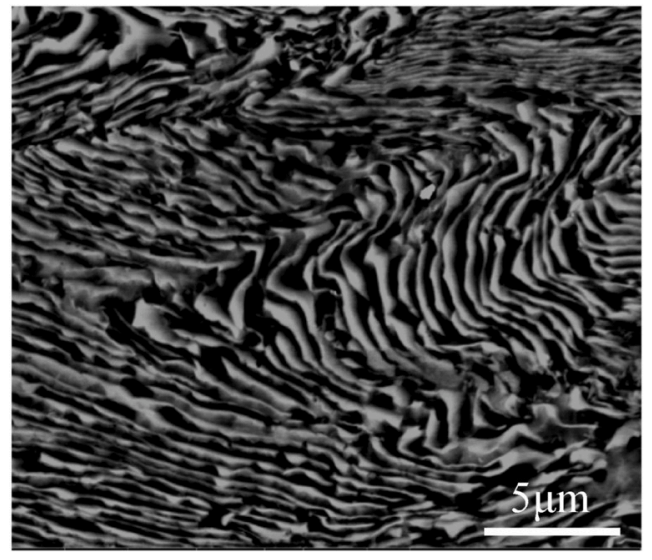

(a)

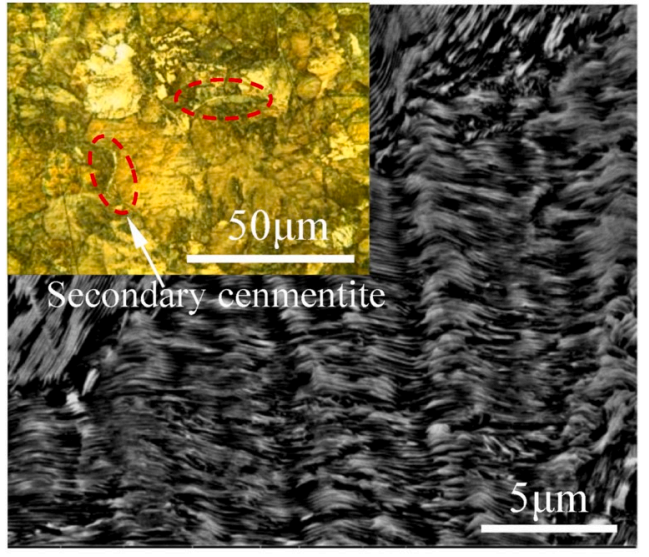

(c)

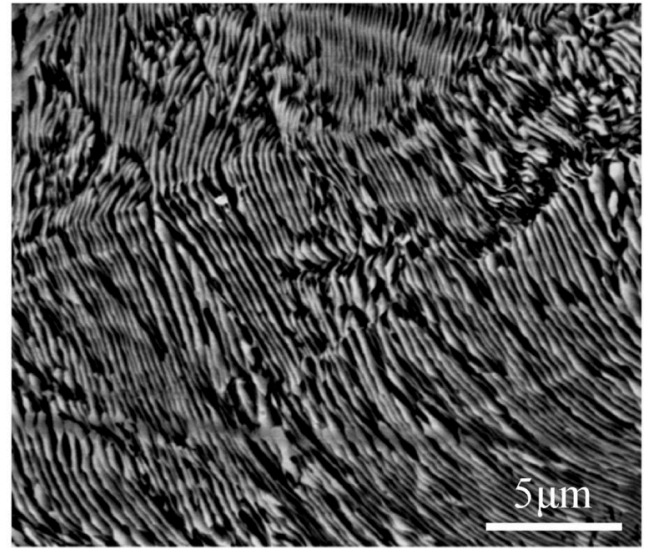

(b)

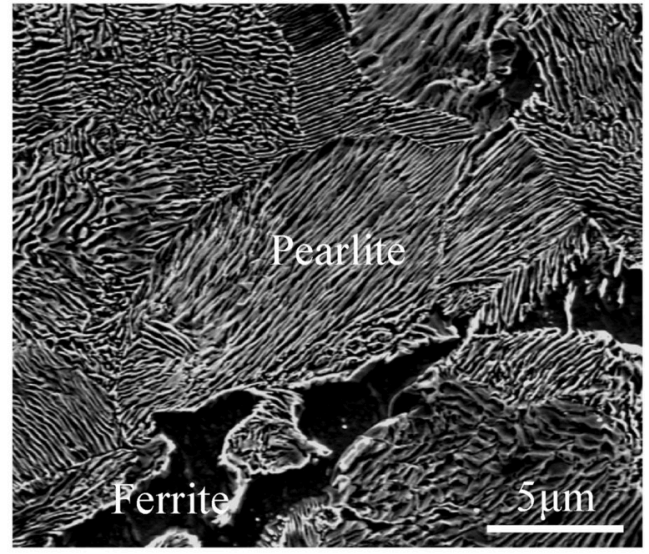

(d)

Fig. 2. Microstructures of rail and wheel materials: (a) rail 1\#; (b) rail 2\#; (c) rail 3\#; (d) wheel.

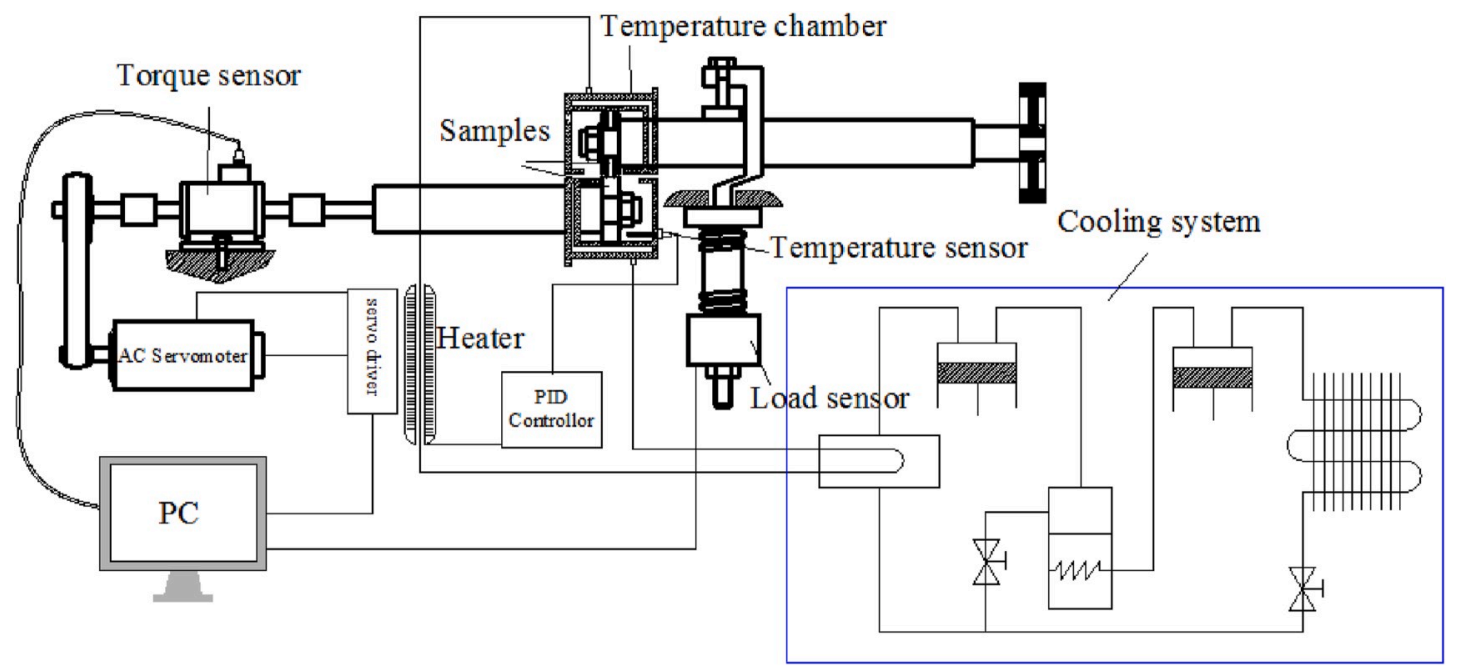

Fig. 3. Schematic diagram of test machine.

roller (rail roller) and lower roller (wheel roller) were driven by an AC servo-motor. Through gear pairs, the difference between wheel and rail speeds could be obtained. In the present study, the rotational speeds of wheel and rail rollers were $200 \mathrm{r} / \mathrm{min}$ and $195.24 \mathrm{r} / \mathrm{min}$, respectively. The slip ratio in this test is defined by the following formula:

Slip ratio $=\frac{\omega_{\text {lower }} \cdot r_{\text {lower }}-\omega_{\text {upper }} \cdot r_{\text {upper }}}{\omega_{\text {lower }} \cdot r_{\text {lower }}}=\frac{\omega_{\text {lower }}-\omega_{\text {upper }}}{\omega_{\text {lower }}}$ where, $\omega_{\text {upper }}$ and $\omega_{\text {lower }}$ are the rotational speeds of wheel and rail rollers, respectively; $r_{\text {upper }}$ and $r_{\text {lower }}$ are the radius of upper and lower rollers (i.e., $40 \mathrm{~mm}$ ). The normal load was applied though a spring. A torque sensor (TQ660, $0 \sim \pm 20 \mathrm{~N} \cdot \mathrm{m}$ ) was installed on the lower shaft to record the tangential force. The cooling system could provide the cold medium to the environment chamber. A PID temperature controller was used to stabilize the temperature inside the environment chamber at the set 
Table 3

Details of test parameters.

\begin{tabular}{lllllll}
\hline $\begin{array}{l}\text { Test } \\
\text { No. }\end{array}$ & Rail & Temperature $/{ }^{\circ} \mathrm{C}$ & $\begin{array}{l}\text { Slip } \\
\text { ratio/ } \\
\%\end{array}$ & $\begin{array}{l}\text { Rotation } \\
\text { speed(r/ } \\
\text { min) }\end{array}$ & $\begin{array}{l}\text { Maximum } \\
\text { contact } \\
\text { pressure/ } \\
\text { MPa }\end{array}$ & $\begin{array}{l}\text { No. of } \\
\text { cycles }\end{array}$ \\
\hline 1 & $1 \#$ & -40 & 2.38 & 200 & 860 & $10^{5}$ \\
2 & $2 \#$ & -40 & & & & \\
3 & $3 \#$ & -40 & & & & \\
4 & $1 \#$ & 20 & & & & \\
5 & $2 \#$ & 20 & & & & \\
6 & $3 \#$ & 20 & & & & \\
\hline
\end{tabular}

value and the variation of temperature was less than $\pm 2{ }^{\circ} \mathrm{C}$. A temperature-humidity sensor was installed in the environment chamber so that the temperature and relative humidity could be monitored.

In this study, three rail steels (rail $1 \#$, rail $2 \#$ and rail $3 \#$ ) were tested under two temperatures: room temperature (around $20^{\circ} \mathrm{C}$ ) and low temperature $\left(-40^{\circ} \mathrm{C}\right)$. All tests were performed under the normal force of $1060 \mathrm{~N}$ (leading to the maximum contact pressure of $860 \mathrm{MPa}$ according to Hertzian simulation theory) with a rotational speed of 200 $\mathrm{r} / \mathrm{min}$ for $1.0 \times 10^{5}$ cycles. The slip ratio between wheel and rail rollers was $2.38 \%$. The details of test parameters are summarized in Table 3 . Each test was carried out at least twice.

Before and after testing, all samples were cleaned in ethanol, dried by

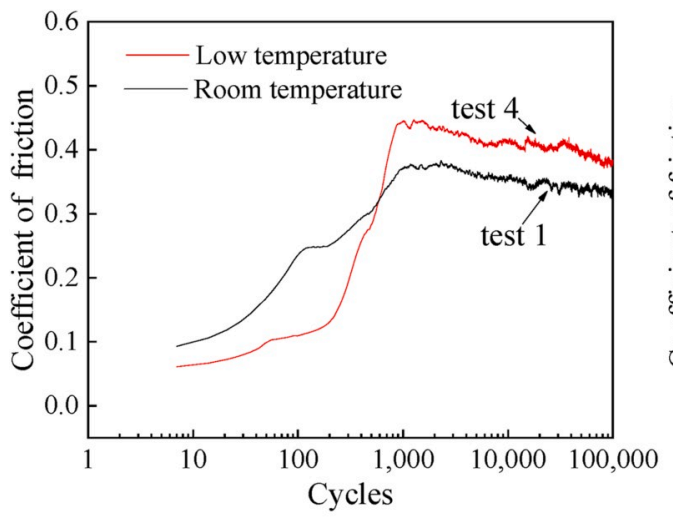

(a)

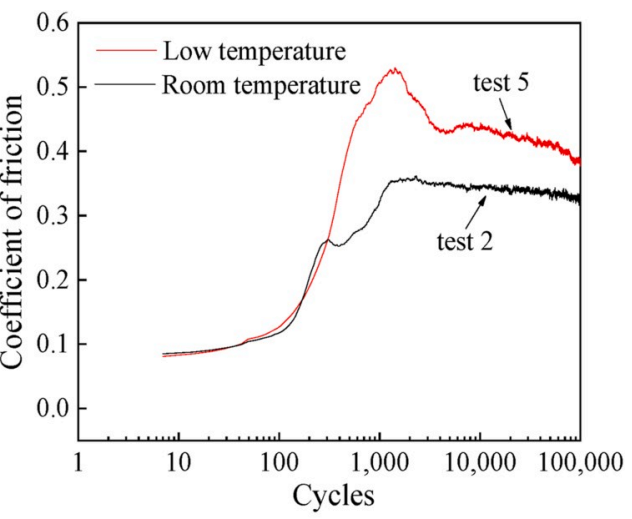

(b)

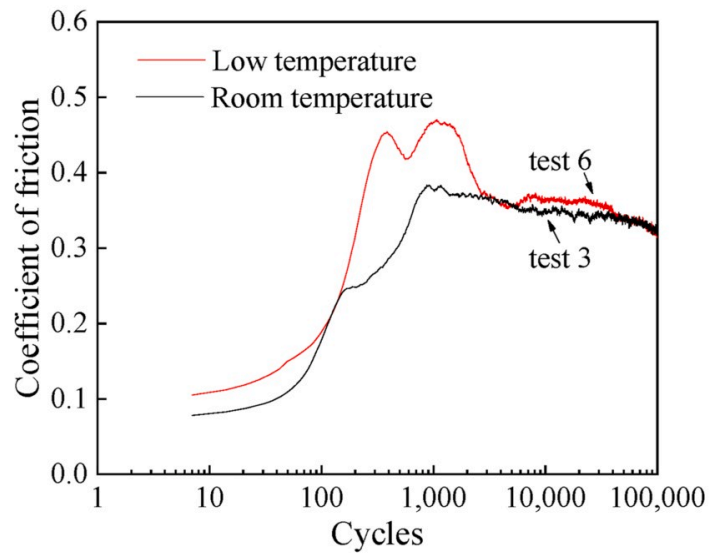

(c)

Fig. 4. COFs of three rail materials at room and low temperatures: (a) rail 1\# vs. wheel; (b) rail 2\# vs. wheel; (c) rail 3\# vs. wheel.

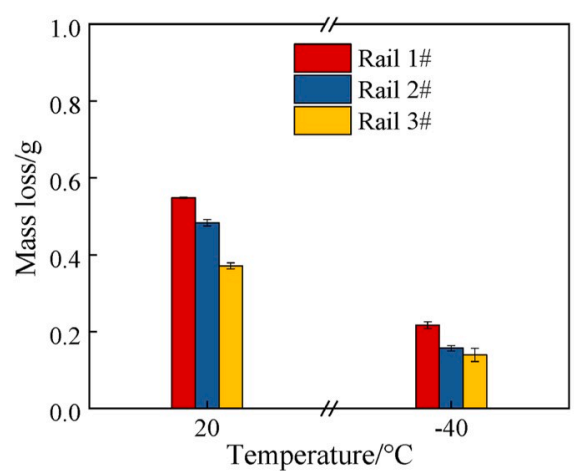

(a)

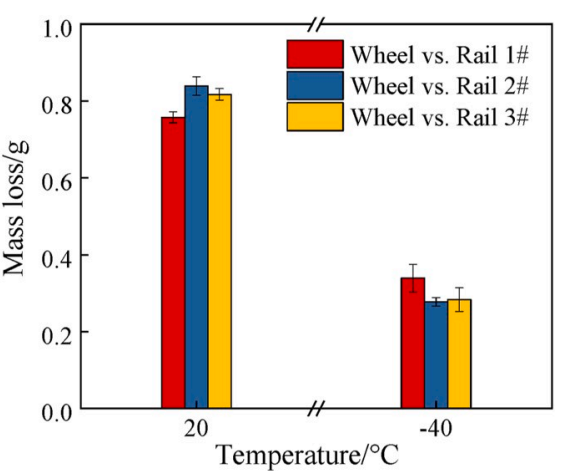

(b)

Fig. 5. Mass losses of (a) rail rollers and (b) corresponding wheel rollers at the room and low temperatures. 


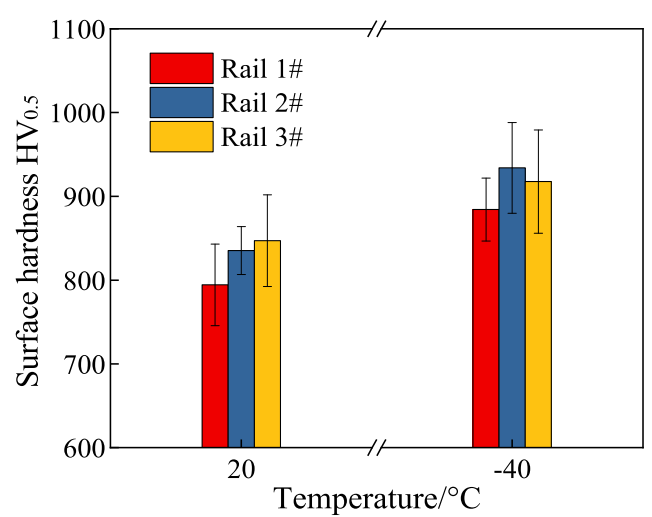

(a)

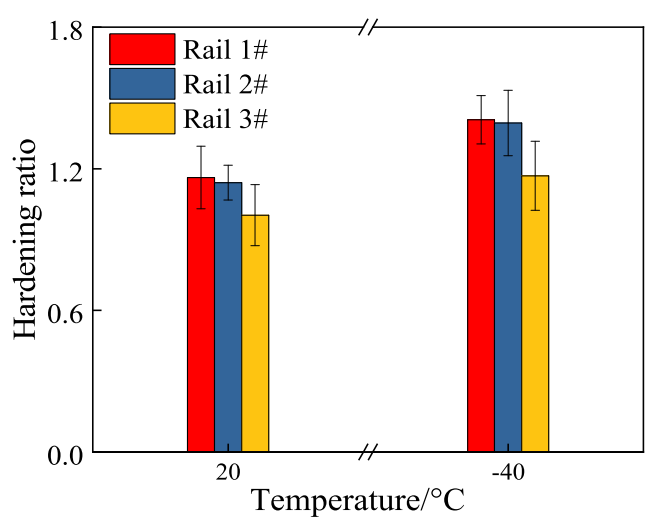

(b)

Fig. 6. Surface hardness and hardening ratio of rails: (a) surface hardness after test; (b) hardening ratio.

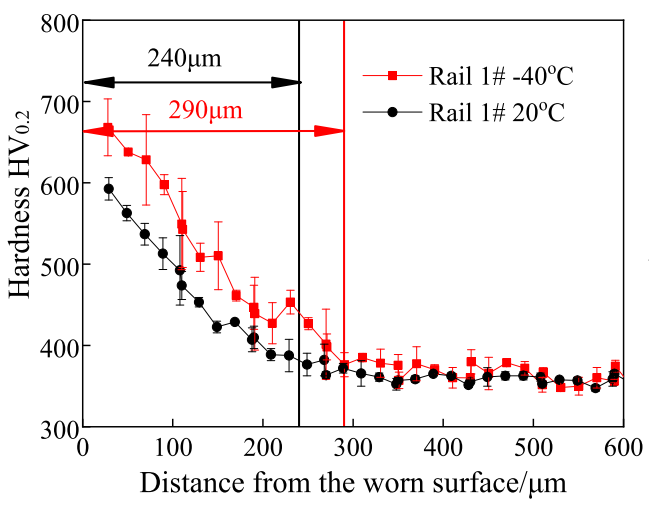

(a)

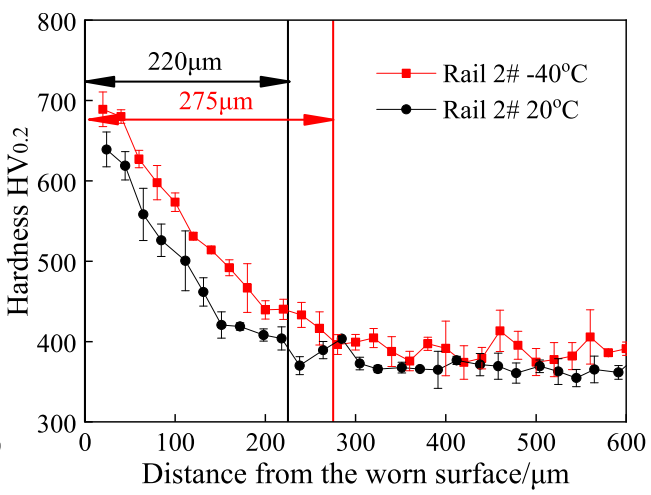

(b)

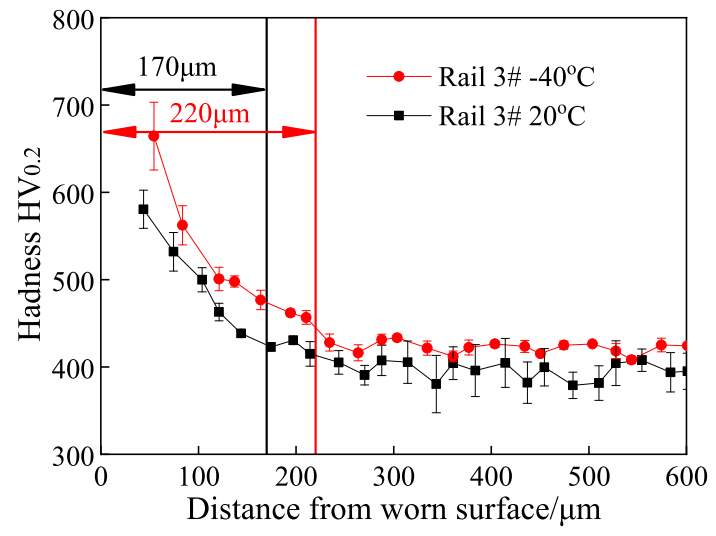

(c)

Fig. 7. Hardness as a function of depth from worn surface: (a) rail 1\#; (b) rail $2 \#$; (c) rail $3 \#$.

hot air and massed via an electronic balance (JA4103, accuracy: $0.0001 \mathrm{~g}$ ). The surface and subsurface hardness were measured through a Vickers hardness machine (MVK-H21, Japan). After the test, samples were cut using a wire cutting machine along the longitudinal direction and then ground, polished and etched (Nital, 4\%) for the observation of the plastic deformation and subsurface damage via an optical microscope (OM) (OLYMPUS BX60 M, Japan) and a scanning electron microscope (SEM) (SM-6490LV, Japan). Chemical compositions of the wheel worn surface were detected via energy dispersive X-ray spectroscopy (EDS) (OXFROD X-Max 80).

\section{Results}

\subsection{Friction coefficient and wear rate}

Fig. 4 shows the evolutions of coefficients of friction (COF) as a function of cycle number of these three kinds of rail materials running against the wheel material at the room (around $20^{\circ} \mathrm{C}$ ) and low $\left(-40^{\circ} \mathrm{C}\right.$ ) temperatures. At the room temperature (black curves), the COFs of these three kinds of rails increase sharply at the beginning of the test and then keep steady until the end of the test at about 0.33 . No clear difference is observed on the COFs at the room temperature. However, the COFs obtained at the low temperature (red curves) are different among the 

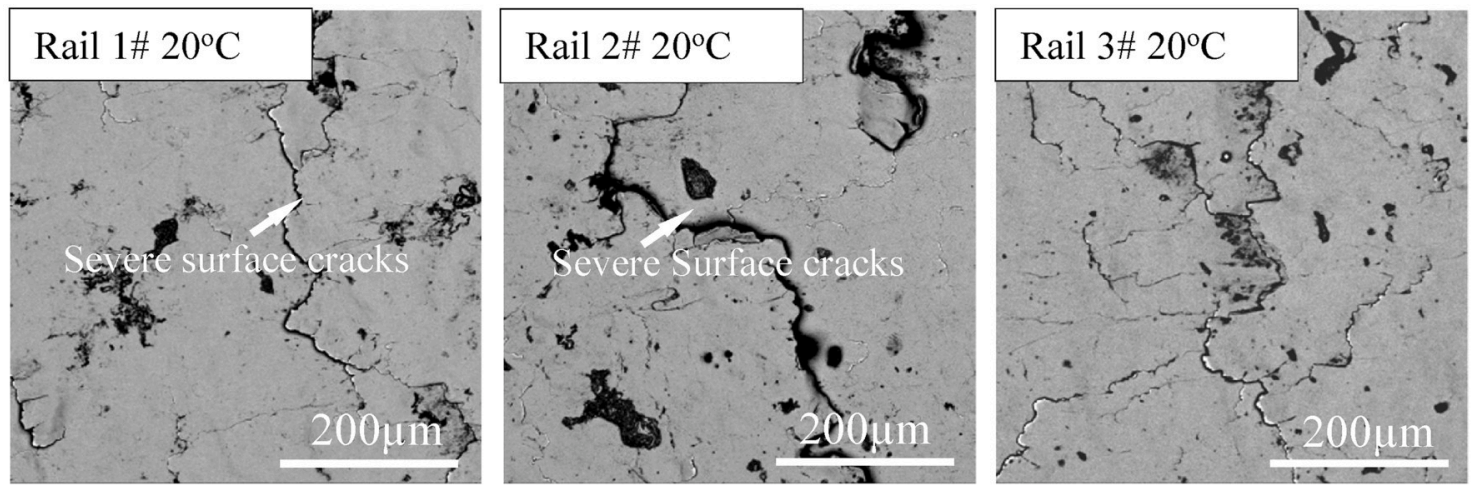

(a)
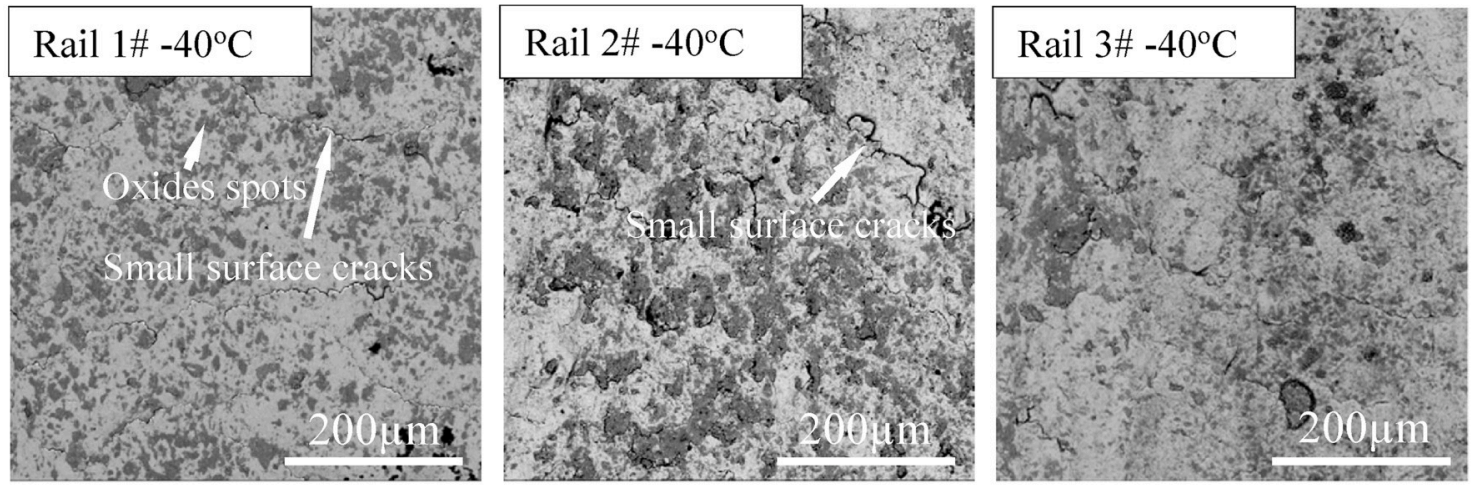

(b)
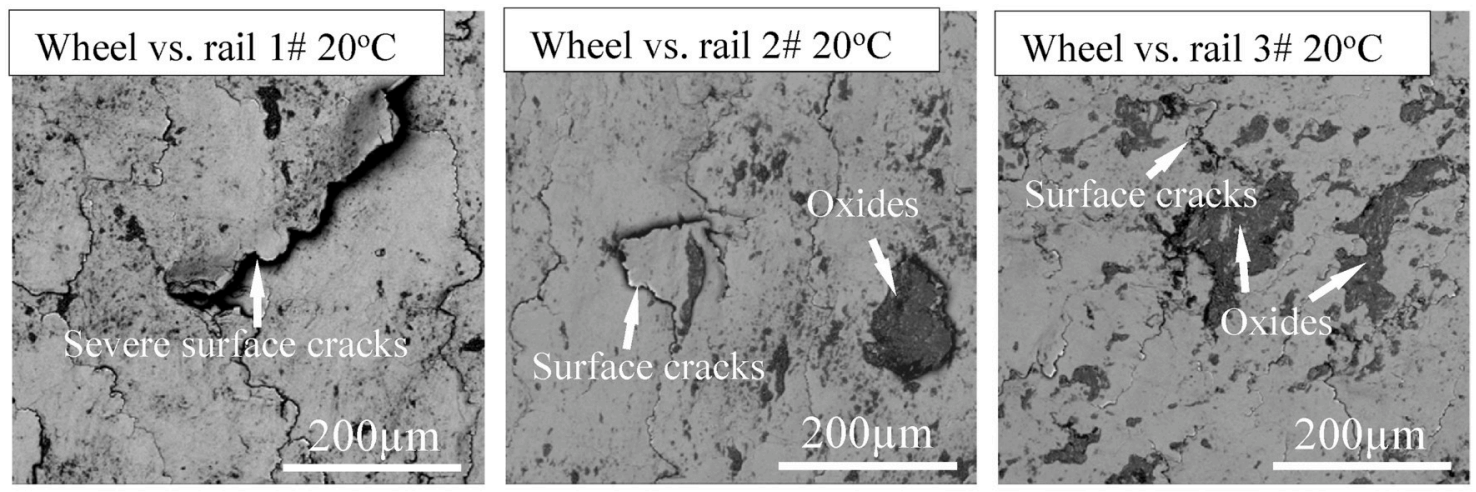

(c)
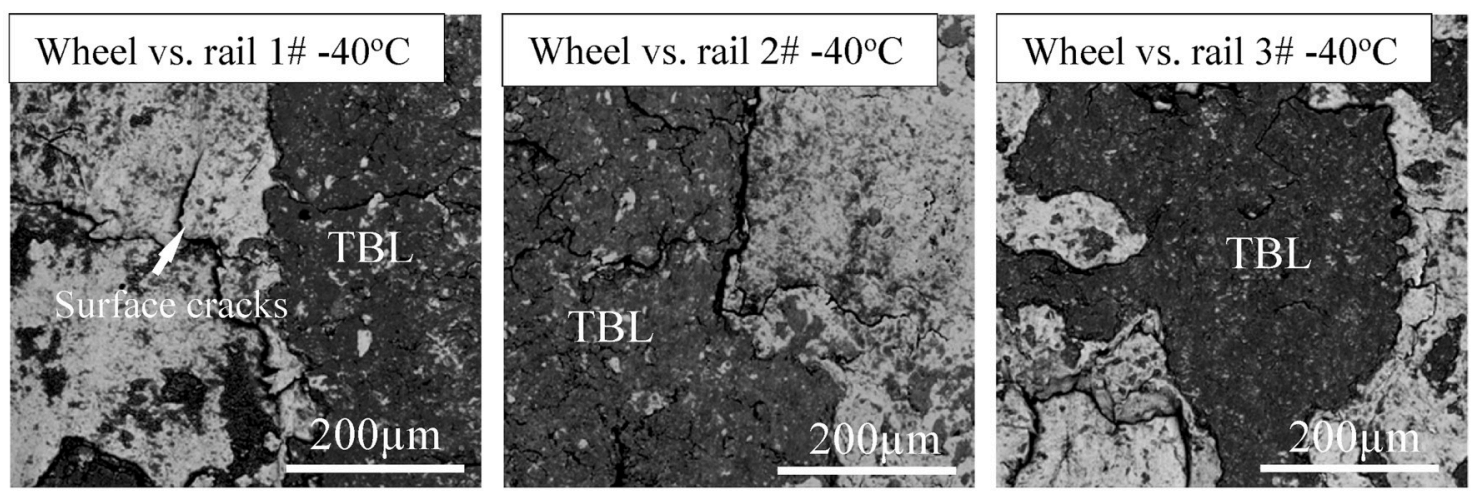

(d)

Fig. 8. Worn surfaces of rails after testing at the (a) room and (b) low temperature, and corresponding wheels at the (c) room and (d) low temperatures. 


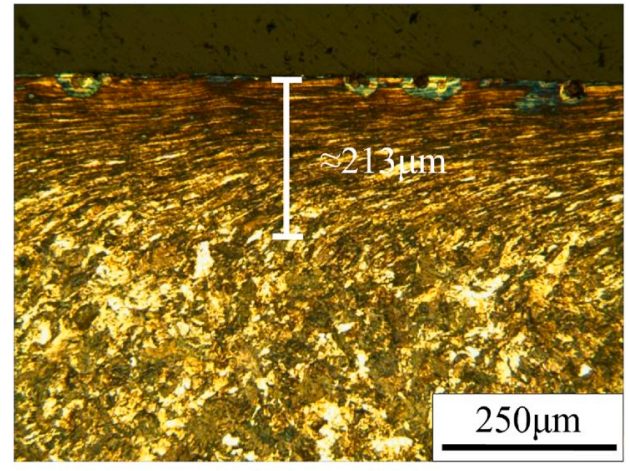

(a)

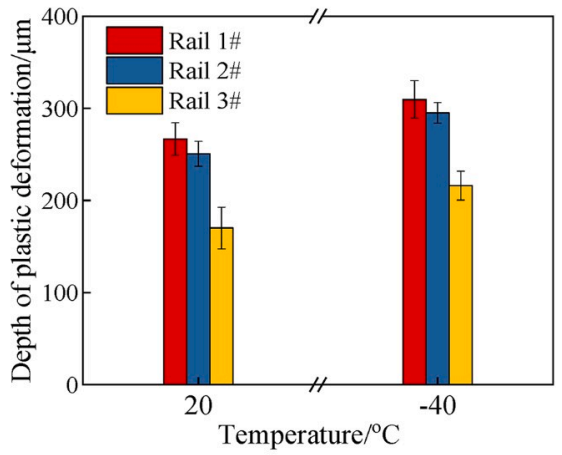

(b)

Fig. 9. (a) Representative OM image of plastic deformation of rail; (b) the thickness of plastic deformation of rails at room and low temperatures.
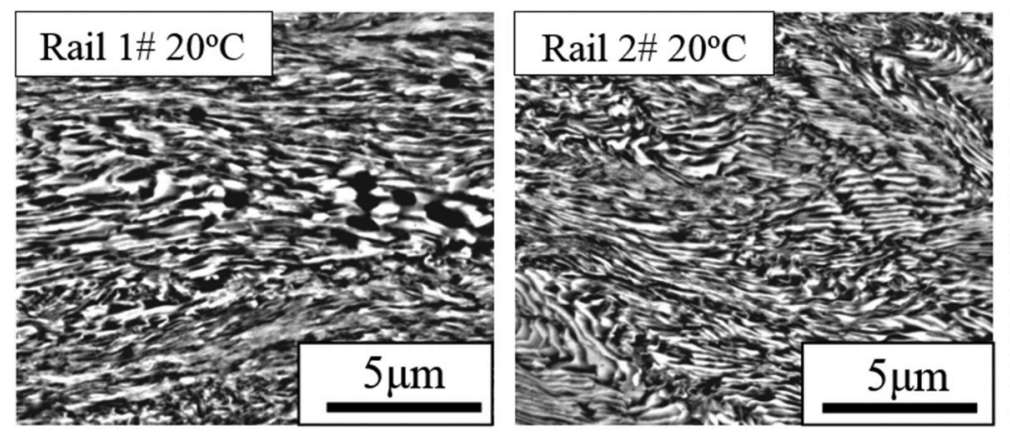

(a)
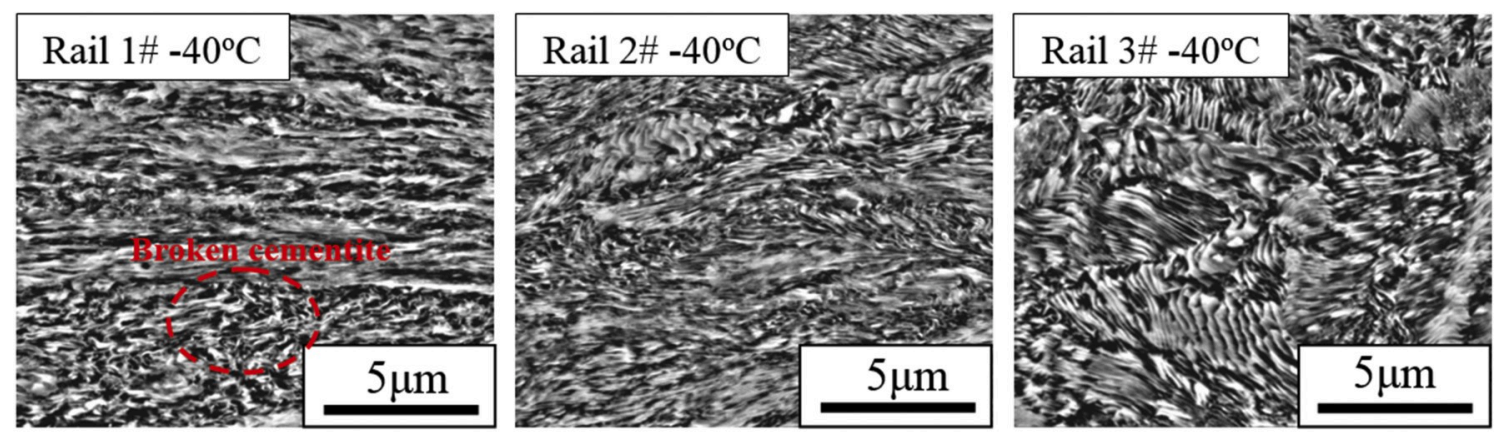

(b)

Fig. 10. SEM observations of plastic deformation of rails at the depth of $150 \mu \mathrm{m}$ : (a) at room and (b) at low temperature environment.

three kinds of rail materials. The COFs for test 5 and test 6 (rail $2 \#$ vs. wheel and rail $3 \#$ vs. wheel at the low temperature) reach maximum values in the running-in period (0-1300 cycles), which are larger than those at the room temperature. For tests 4 and 5 (rail 1 \# vs. wheel and rail $2 \#$ vs. wheel), the COFs in the steady state are higher than those under the room temperature condition, while the COF of test 6 (rail 3\# vs. wheel) shows no clear difference with that under the room temperature condition (test 3 ).

The mass losses of the three rail materials and the corresponding wheel after testing at the room and low temperatures are shown in Fig. 5. It is obvious that both the material type and temperature have influences on the wear of rail materials. The mass losses of wheel and rail rollers at the low temperature are obviously smaller than those at the room temperature. Under both the room and low temperature conditions, the hypereutectoid rail steel (rail 3\#) shows a better wear resistance than the eutectoid rail steels (rail 1\# and rail 2\#). Furthermore, the mass loss of rail roller is milder than that of wheel roller. Concerning the corresponding wheel rollers, the mass loss of the wheel roller running against the rail $1 \#$ is smaller at the room temperature but larger at the low temperature than those of other wheel rollers running against the rail $2 \#$ and rail $3 \#$. The change of mass loss obtained at room and low temperatures is consistent with reference [17] but opposite to Refs. [19]. The possible reason for the difference between the present study and reference [19] is that TBLs were formed at wheel and rail interfaces during testing at the low temperature in this study but no TBLs were formed in Refs. [19] due to the different test parameters and materials. The formation mechanism of TBL will be discussed in detail later.

\subsection{Hardening behavior of rails}

The surface hardness of the three kinds of rails increased significantly after the rolling-sliding test. Surface hardness and hardening ratio (surface hardness after testing divided by the initial hardness) of the three kinds of rails are shown in Fig. 6 . It is clear that the rail material 

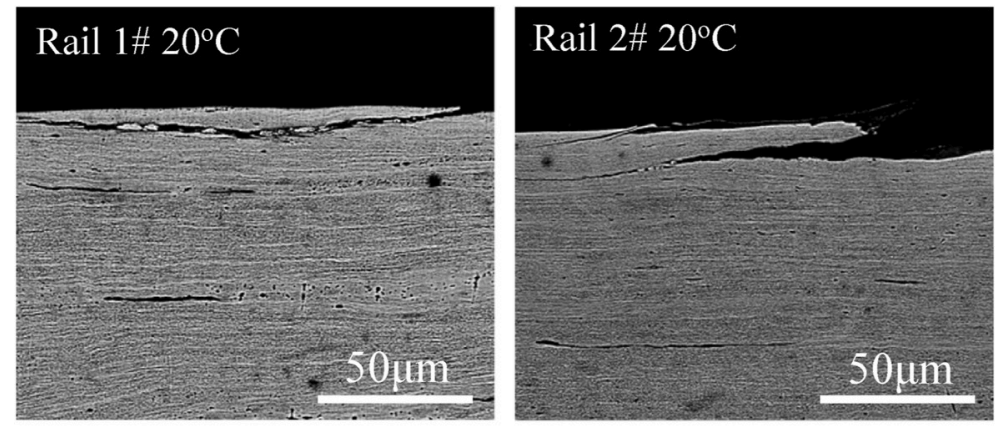

(a)
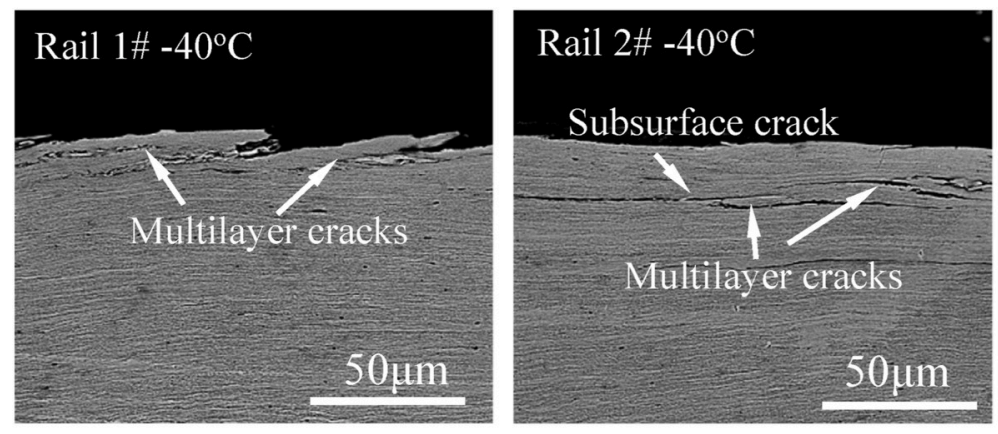

(b)
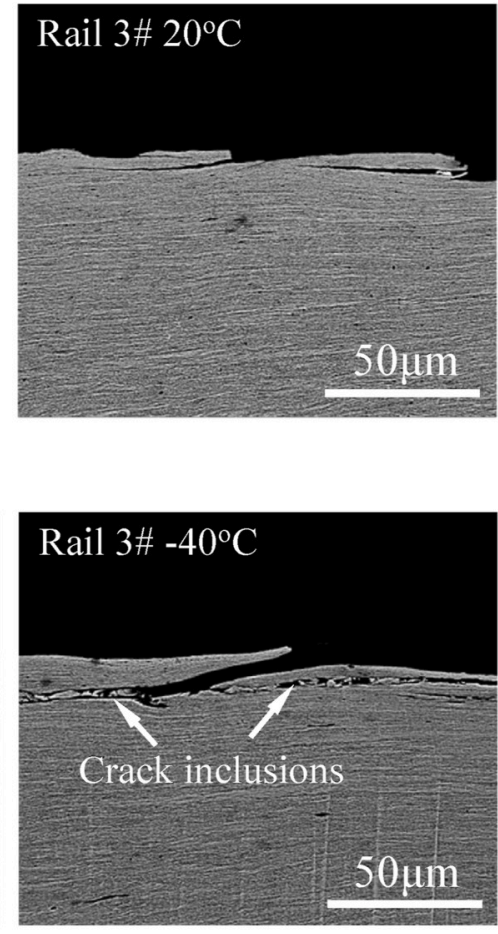

Fig. 11. SEM observations of subsurface cracks of rails: (a) at room and (b) at low temperatures.

Table 4

Average and maximum crack length of rails.

\begin{tabular}{|c|c|c|c|c|c|c|}
\hline & \multicolumn{3}{|c|}{ Room temperature } & \multicolumn{3}{|c|}{ Low temperature } \\
\hline & $\begin{array}{l}\text { Rail } \\
1 \#\end{array}$ & $\begin{array}{l}\text { Rail } \\
2 \#\end{array}$ & $\begin{array}{l}\text { Rail } \\
3 \#\end{array}$ & $\begin{array}{l}\text { Rail } \\
1 \#\end{array}$ & $\begin{array}{l}\text { Rail } \\
2 \#\end{array}$ & $\begin{array}{l}\text { Rail } \\
3 \#\end{array}$ \\
\hline $\begin{array}{l}\text { Average crack } \\
\text { length } / \mu \mathrm{m}\end{array}$ & $\begin{array}{l}81 \pm \\
56\end{array}$ & $\begin{array}{l}149 \pm \\
86\end{array}$ & $\begin{array}{l}49 \pm \\
16\end{array}$ & $\begin{array}{l}46 \pm \\
31\end{array}$ & $\begin{array}{l}63 \pm \\
38\end{array}$ & $\begin{array}{l}66 \pm \\
41\end{array}$ \\
\hline $\begin{array}{l}\text { Maximum crack } \\
\text { length } / \mu \mathrm{m}\end{array}$ & 213 & 364 & 80 & 161 & 180 & 187 \\
\hline
\end{tabular}

type and the temperature have influence on the hardening behavior of rail rollers. As shown in Fig. 6(a), the surface hardness of rails after testing at the room temperature increases with the increase in the initial rail hardness. Moreover, the surface hardness of rails after testing at the low temperature is higher than that at the room temperature. The hardening ratio of these three kinds of rails at the low temperature is higher than that at the room temperature (Fig. 6(b)). Besides, the hardening ratio of rail $3 \#$ is smaller than those of rail $1 \#$ and rail $2 \#$.

Fig. 7 shows the hardness of the three kinds of rails on the cross section after testing at the room and the low temperatures. It can be seen that the hardness is higher at the outermost layer, and then decreases gradually (which is referred to the hardening layer) to the level of substrate hardness. The thickness of the hardening layer of these three kinds of rails is in the range of $170-290 \mu \mathrm{m}$. With the increase in the initial hardness of rails (from rail $1 \#$ to rail $2 \#$ and to rail $3 \#$ ), the thickness of hardening layer decreases. In addition, the thickness of hardening layer of the hypereutectoid rail steel (rail 3\#) is lower than those of the eutectoid steels (rail 1\# and rail 2\#). Finally, in the hardening layer the hardness values at the same depth after testing at the low temperature are higher than those at the room temperature.

\subsection{Surface damage}

Fig. 8 shows the worn surfaces of the three rail materials and the corresponding wheel material after testing at the room and low temperatures. It is obvious that the temperature influences the surface damage of wheel and rail materials. In the room temperature environment, the surface damages of the three kinds of rail materials are dominated by severe surface cracks (Fig. 8(a)) and the influence of material type is not obvious. As for the corresponding wheel rollers, the surface damages are dominated by surface cracks and oxides (Fig. 8(c)). Besides, with the increase in the initial rail hardness, the wheel surface cracks alleviate but more oxides are observed. On the contrary, in the low temperature environment, the surface damages of the three kinds of rails are dominated by small surface cracks and oxidized spots (Fig. 8 (b)), and the surface cracks are much milder than those at the room temperature. Concerning the surface damage of the corresponding wheel rollers at the low temperature, except for the surface cracks, a large area of the worn surface is covered by discontinuous TBLs (Fig. 8 (d)).

\subsection{Plastic deformation}

Fig. 9(a) shows a representative OM image of plastic deformation of rail (rail $3 \#$ at the low temperature). The thickness of plastic deformation is in the range of $170-310 \mu \mathrm{m}$, which is consistent with the hardening layer thickness (Fig. 7). Fig. 9(b) shows the thickness of plastic deformation for all the rail materials. It can be seen that the depth of plastic deformation of rail after testing at the low temperature is larger than that at the room temperature. With the increase in initial rail hardness (from rail $1 \#$ to rail $2 \#$ and to rail $3 \#$ ), the depth of plastic deformation decreases both at the room and low temperatures. The hypereutectoid rail (rail $3 \#$ ) shows a better plastic deformation resistance than that of eutectoid rail steels.

Fig. 10 shows the SEM images of deformed microstructures of the three kinds of rail samples along the rolling direction at the depth of 150 $\mu \mathrm{m}$, which is near the transition zone between the substrate and the severe deformation zone. As shown in Fig. 2, the initial microstructures of the three kinds of rail steels are mainly pearlite structures. After the 

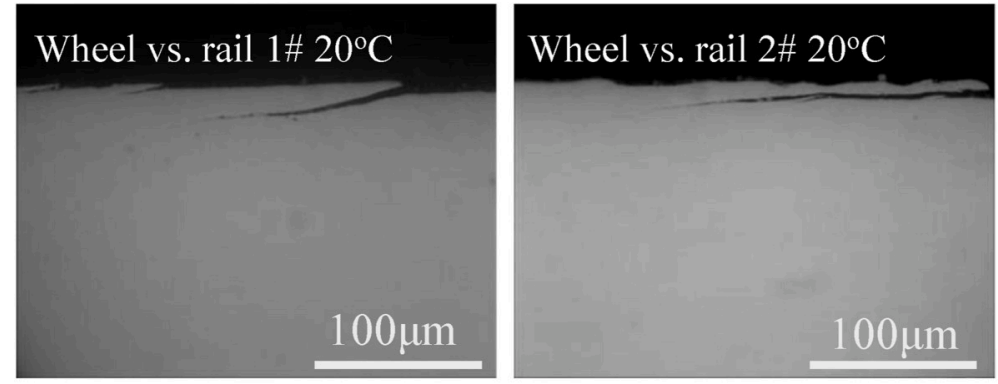

(a)
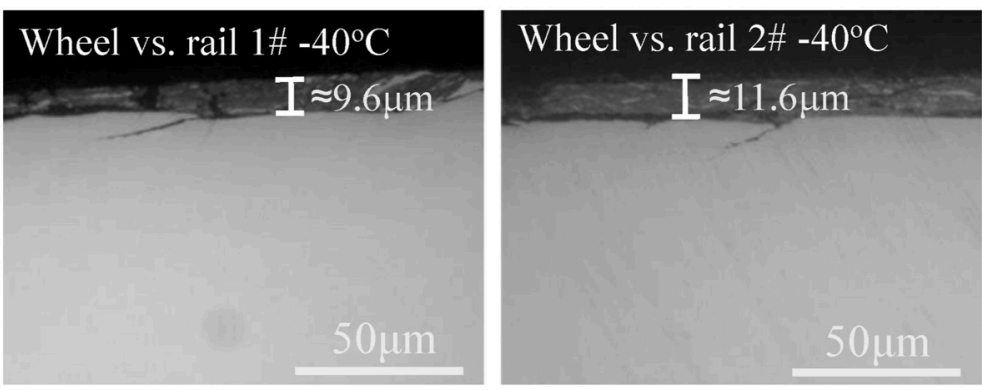

(b)
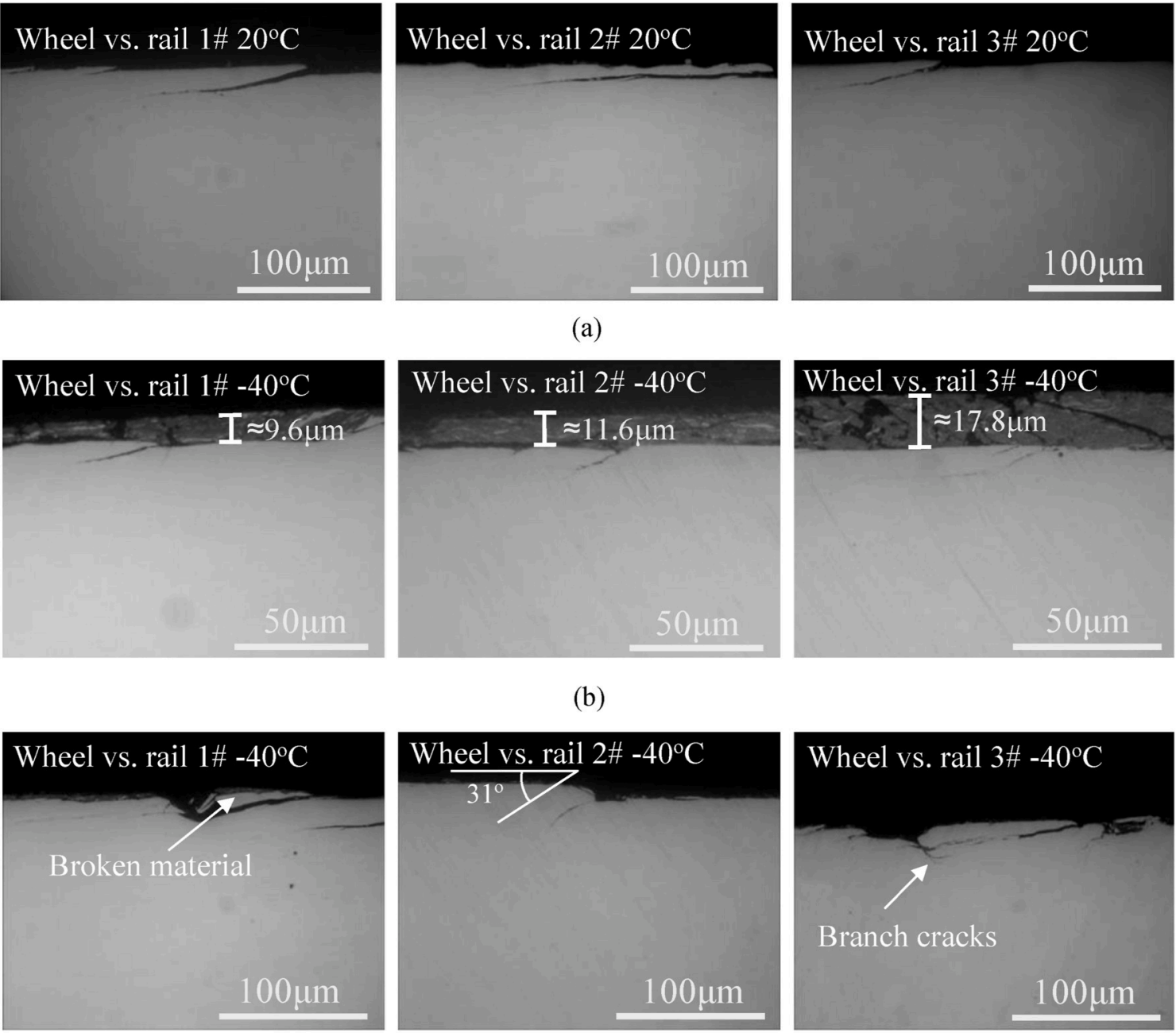

(c)

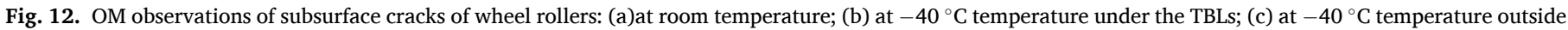
the TBLs zone.

rolling-sliding testing, the cementites are curled and broken (Fig. 10). It is clear that both the rail material type and the temperature have influences on the microstructure deformation of rails. With the increase in initial rail hardness, the fraction of broken cementites decreases and the fraction of curled cementites increases. At the room temperature, eutectoid steels are dominated by continued broken cementites and the hypereutectoid steel is dominated by curled cementites. At the low temperature, eutectoid steels are still dominated by continued broken cementites and the hypereutectoid steel is dominated by short and curled cementites. In summary, the microstructure of hypereutectoid steel (rail 3\#) shows a better deformation resistance than those of eutectoid steels (rail $1 \#$ and rail $2 \#$ ) at both the room and low temperature environments. Furthermore, after testing at the low temperature, the plastic deformation of all the three kinds of rail materials are severer than those at the room temperature.

\subsection{Subsurface damage}

Fig. 11 shows the subsurface cracks on the cross sections of the three kinds of rail materials after testing at the room and low temperatures. At the room temperature (Fig. 11(a)), single long cracks along the plastic flow line are observed on the eutectoid rails (rail 1\# and rail 2\#). In the low temperature environment (Fig. 11(b)), multilayer cracks and subsurface cracks are observed, and the cracks propagation does not strictly follow the plastic flow line. Table 4 shows the statistical results of the average and maximum crack lengths for the three kinds of rail materials. After testing at the room temperature, both the average crack length and the maximum crack length of rail $1 \#$ and rail $2 \#$ are larger than those of rail 3\#. After testing at the low temperature, the crack lengths of rail 1\# and rail $2 \#$ are smaller than those at the room temperature, but the crack length of rail $3 \#$ is larger than that at the room temperature. It can be concluded that the hypereutectoid rail steel has better rolling contact fatigue (RCF) resistance and better wear resistance than eutectoid steels at the room temperature but worse RCF resistance at the low temperature.

Fig. 12 shows the OM images of cracks on wheel rollers. After testing at the room temperature, single cracks can be observed (Fig. 12(a)). On the contrary, after testing at the low temperature, a TBL is formed discontinuously on the wheel surface, as shown in Fig. 8(d). Thus, two types of cracks could be observed on the wheel rollers after testing at the low temperature: (1) cracks under the TBLs have short lengths and small crack opening (Fig. 13(b)); (2) cracks outside the coverage of the TBLs are longer, and branch cracks could be observed (Fig. 12(c)).

\subsection{Debris}

Fig. 13 shows the debris of the three kinds of rail materials running against the considered wheel material at the room and low 

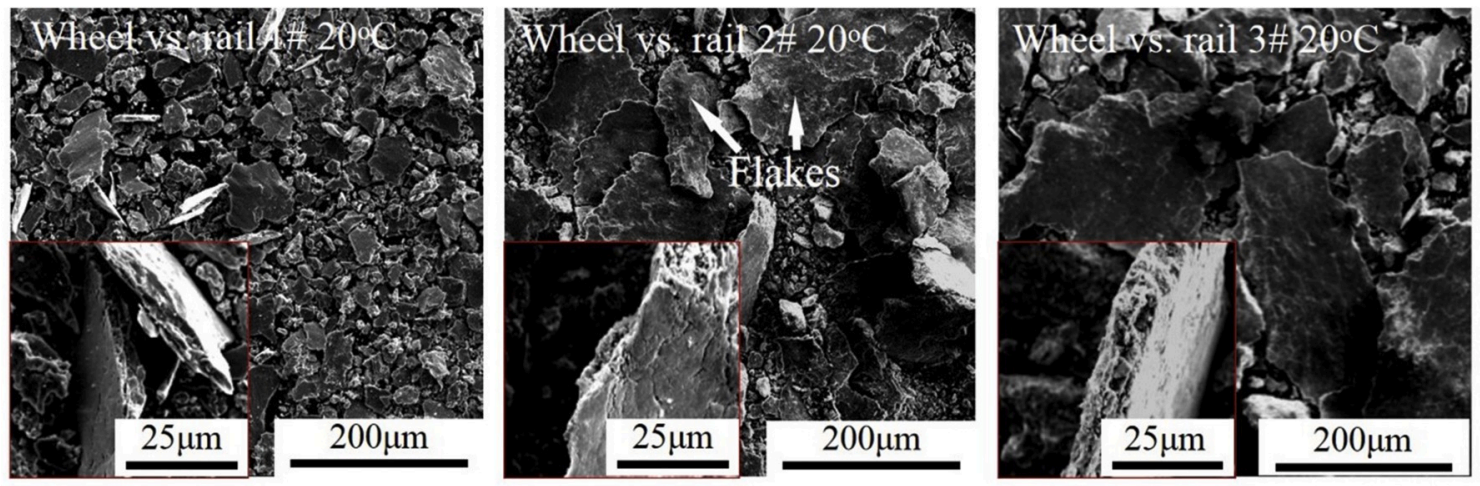

(a)
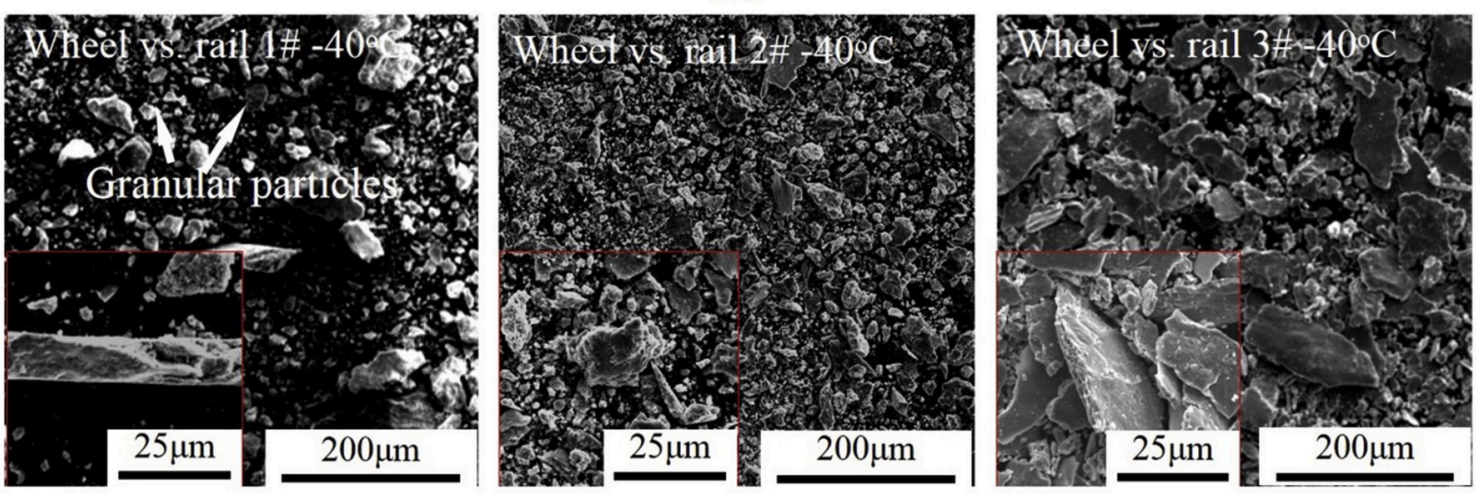

(b)

Fig. 13. SEM images of debris: (a) at room temperature; and (b) at low temperatures.

temperatures. The debris is mainly composed of flakes and granular particles. Both the temperature and rail steel type have influence on the dimension of wear debris. With the increase in the rail hardness (from rail $1 \#$ to rail $2 \#$ and to rail $3 \#$ ), the size of flake increases under both the room and the low temperature conditions. Moreover, the size of debris in low temperature environment (Fig. 13(b)) is smaller than that in the room temperature environment (Fig. 13(a)).

\section{Discussion}

\subsection{The influence of temperature on wear and damages of wheel and rail} materials

The mass losses of the three kinds of rail rollers at the low temperature $\left(-40^{\circ} \mathrm{C}\right)$ were clearly smaller than those at the room temperature (around $20^{\circ} \mathrm{C}$ ) (Fig. 5(a)). Furthermore, at the room temperature, the surface damages of the three kinds of rails were dominated by surface cracks (Fig. 8(a)) and the corresponding wheel rollers were dominated by surface cracks and oxides (Fig. 8 (c)). However, at the low temperature, the surface damages of the three kinds of rails were dominated by small surface cracks and oxides spots (Fig. 8(b)). On wheel rollers, surface cracks were generated and a large area of the worn surface was covered by TBLs (Fig. 8(d)). It was worth noting that the thickness of TBLs (from 9.6 to $17.8 \mu \mathrm{m}$ ) formed at the low temperature was one order of magnitude larger than the roughness of wheel and rail surfaces. Therefore, TBLs protected the wheel/rail rollers against the effects of direct contact. The presence of TBL might result in the decline of mass loss and in the milder surface fatigue damages of wheel and rail rollers at the low temperature observed in the present study.

The effects of wear debris on the friction and wear behaviors of a rubbing surface could be detrimental or palliative, which depends on the dwell time of debris in the contact region [30]. The relative humidity $(\mathrm{RH})$ in environment chamber during the test decreased from $55 \%$ to
$65 \% \mathrm{RH}$ at the room temperature to $9 \%-12 \% \mathrm{RH}$ at the low temperature. At the room temperature (accompanied by higher humidity), moisture was absorbed physically on both the new surface of wheel and rail substrate and the new surfaces of wear particles; therefore the wear debris was ejected easily from the contact area without adhering to the wheel and rail surfaces. Thus, the wear debris formed at the room temperature could not provide a protective effect to the wheel and rail surfaces (Fig. 14(a)), leading to high mass losses and severe surface cracks on wheel and rail rollers. Due to the lack of moisture being absorbed on the contact surfaces at the low temperature, the wear particles had a higher tendency to adhere to the wheel and rail surfaces [31]. Furthermore, finer ejected wear debris was observed (Fig. 13(b)) at the low temperature, which was considered to be beneficial to the formation of a debris bed on the rubbing surface [32]. The presence of the debris bed led to a long dwell time for the wear debris. Therefore, the TBL that formed at the low temperature provided a protective effect to wheel and rail surfaces, as shown in Fig. 14(b). Thus, the low humidity at the low temperature accelerated the formation of TBL which could palliate wear of wheel and rail materials in the present study.

The subsurface damages of rail rollers after testing at the low temperature were different from those at the room temperature. At the room temperature, the cracks mainly propagated along the plastic line (Fig. 11 (a)); however, at the low temperature, multilayer cracks and subsurface cracks were generated (Fig. 11(b)). During the rolling-sliding testing, the surface layer underwent severe plastic deformation and the randomly oriented pearlites were rearranged along the rolling direction, which could lead to a structure anisotropyat the surface layer. Thus, single cracks were developed along the plastic flow line at the room temperature (Fig. 11(a)). However, at the low temperature, as the temperature is lower than DBTT, the brittleness of wheel and rail materials was increased and the ductility was decreased. Furthermore, the effect of thermal softening cannot be neglected [33,34]. Due to the lower temperature environment, the maximum temperature beneath the 


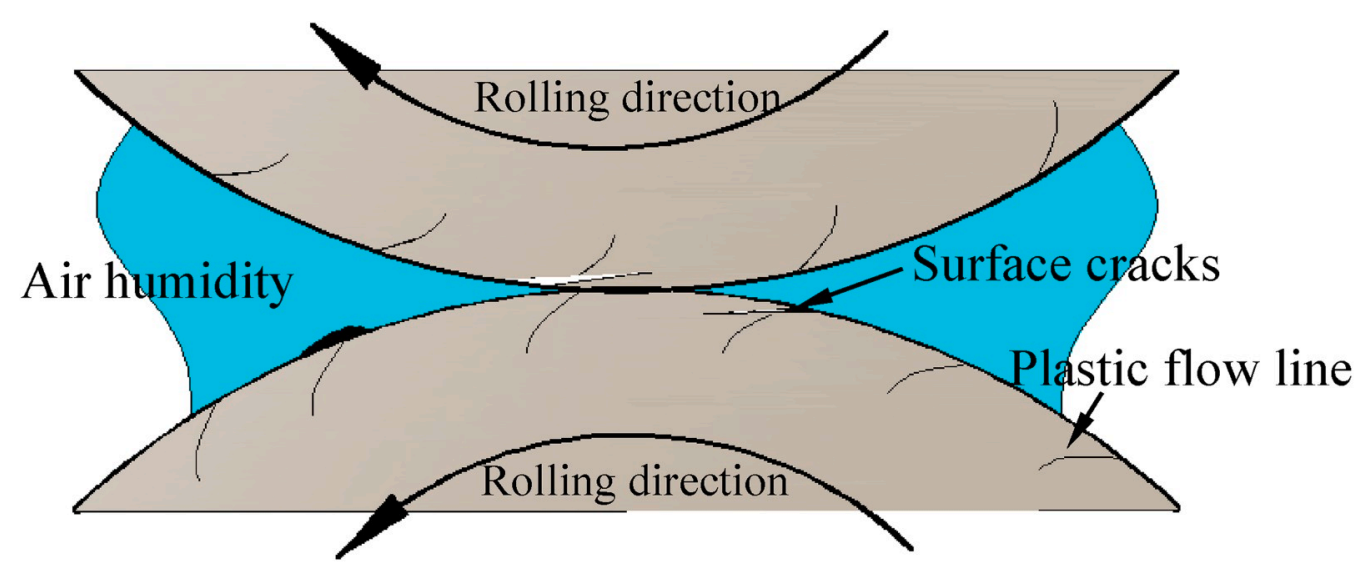

(a)

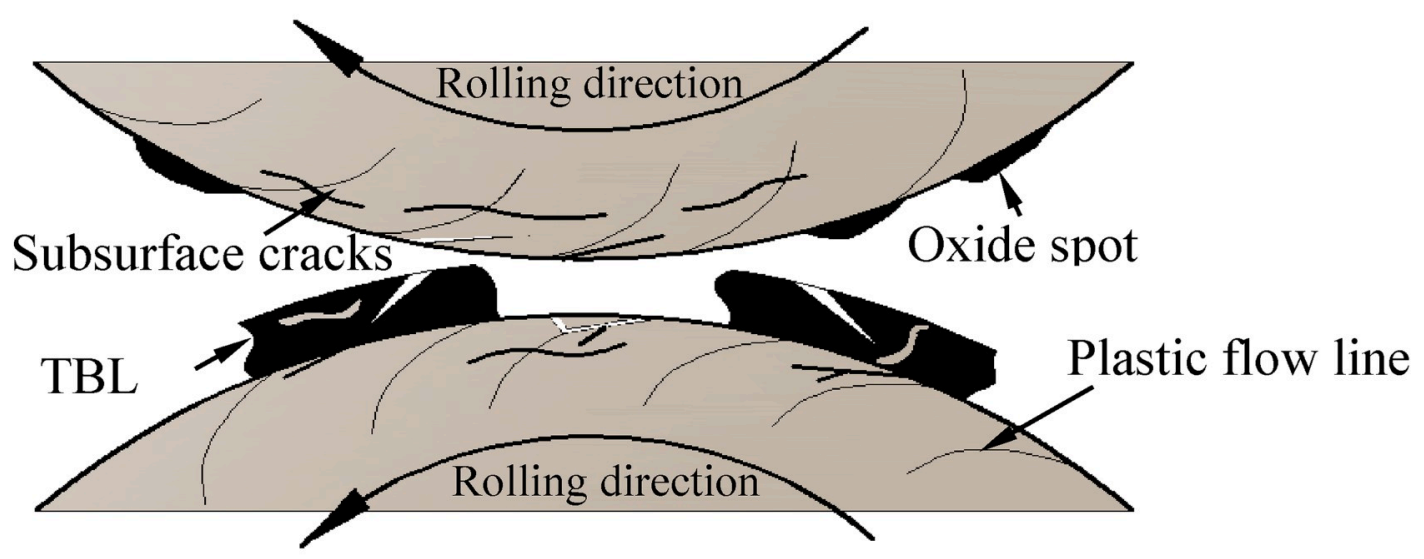

(b)

Fig. 14. Wear processes of wheel/rail at: (a) room temperature; (b) low temperature.

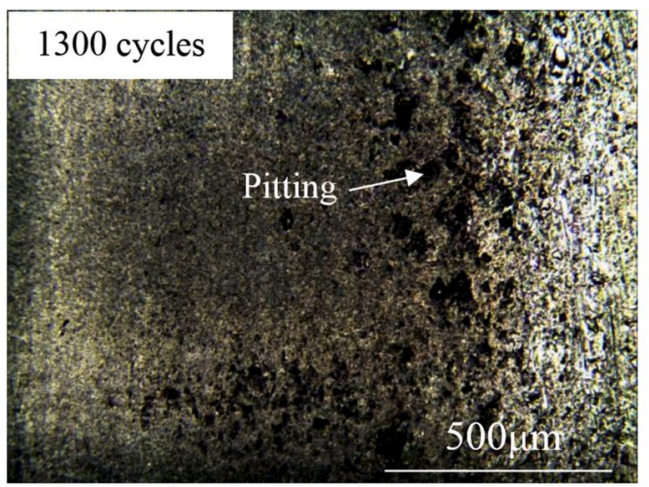

(a)

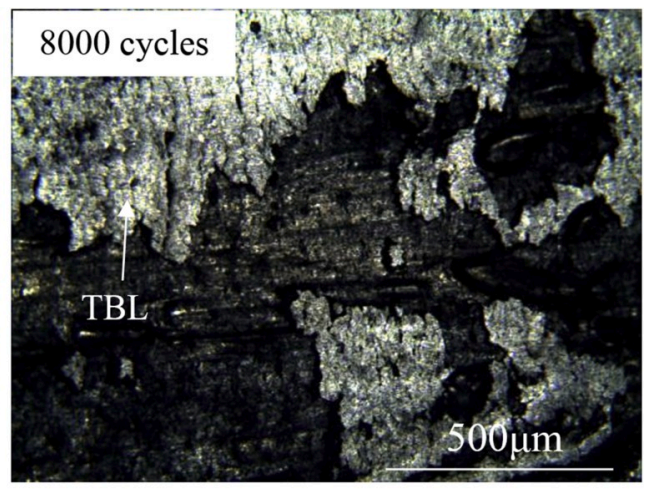

(b)

Fig. 15. The evolution of wheel surface: (a) running-in period; (b) steady state.

Table 5

Chemical composition of TBL and wheel surface outside TBL at the low temperature (at $\%)$.

\begin{tabular}{llllll}
\hline Detected zone & C & Fe & O & Si & Mn \\
\hline TBL on wheel & 10.0 & 39.8 & 49.2 & 0.7 & 0.3 \\
Wheel surface outside TBL & 16.1 & 79.6 & 2.4 & 1.3 & 0.6 \\
\hline
\end{tabular}

contact area during rolling and sliding was lower at the low temperature than at the room temperature. Thus, at the low temperature, the thermal softening on the wheel/rail surfaces was weakened, which might lead to the higher work hardening rate (Fig. 6(b)) and the severer microstructure deformation of rail rollers (Fig. 10). Under the rolling-sliding contact condition, work hardening occurs as a result of dislocation strengthening and grain refinement. Highly deformed grains had priority over coarse grains on crack nucleation and propagation [24]. As a result, subsurface cracks and multilayer cracks were easily initiated and 

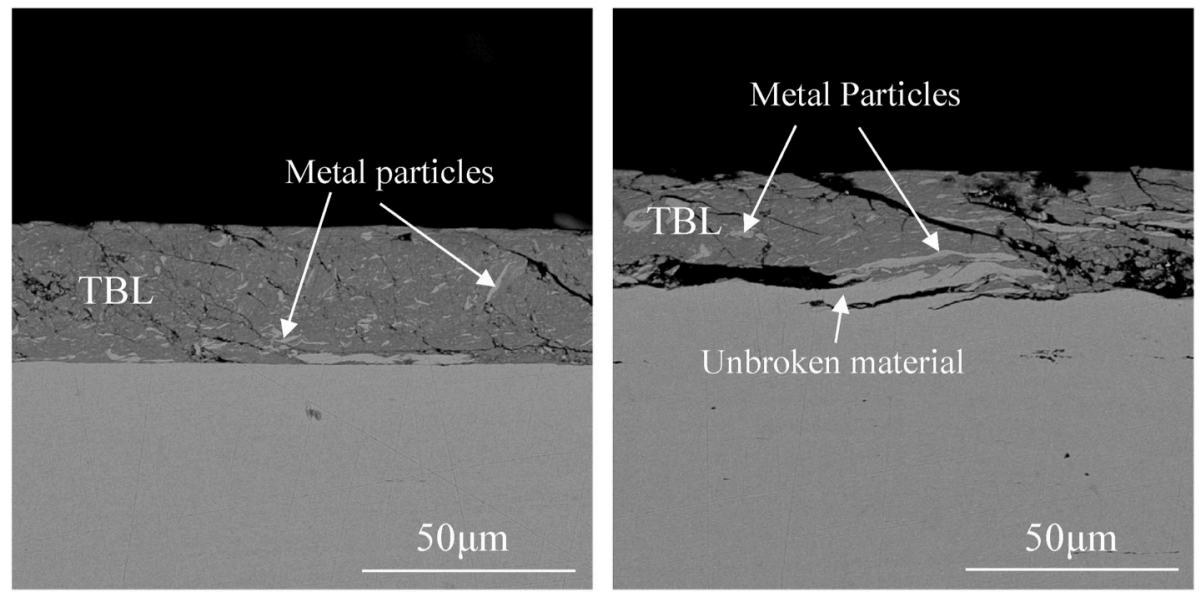

Fig. 16. SEM images of TBL on cross sections.

propagated in this layer at the low temperature.

\subsection{Comparison between hypereutectoid steel and eutectoid steels}

Among these three kinds of rails, the hypereutectoid steel (rail 3\#) had the highest hardness $\left(423 \mathrm{HV}_{0.5}\right)$. At the room temperature, the wear rate, hardening layer thickness, and hardening rate of hypereutectoid rail steel were lower than those of eutectoid steels. These trends were similar to the results in the previous work [35]. Furthermore, the crack length of hypereutectoid rail steel was smaller than that of eutectoid steels (Table 4). So, it can be concluded that the hypereutectoid rail steel had better wear resistance and RCF resistance than eutectoid steels at the room temperature.

At the low temperature, the hypereutectoid rail steel still had lower wear rate, hardening layer thickness, and hardening rate than those of eutectoid steels. However, in the low temperature environment, the brittleness of rail materials was dominant in crack propagation [19]. Due to the lower ductility (Table 2), the hypereutectoid steel had a longer crack length than that of eutectoid steels. Consequently, the hypereutectoid rail steel had a better wear resistance but a worse RCF resistance with respect to eutectoid steels at the low temperature.

\subsection{The formation of TBL}

COFs at the low temperature reached the maximum value and then decreased suddenly for test 5 and test 6 (Fig. 4). The decrease of COF might be related to the formation of TBL on the wheel surface. Consequently, tests with smaller numbers of cycles (under the same conditions of test 6) were carried out to observe the evolution of wheel surface, as shown in Fig. 15. After 1300 cycles (during the running-in period), the surface was clean and the surface damage was dominated by pitting (Fig. 15(a)). However, with the increase in cycles, a large area of the wheel surface was covered by the TBL (Fig. 15(b)). The high COF value in the running-in period at the low temperature might be due to the low humidity for low temperatures. In a low humidity surrounding atmosphere, a strong adhesion strength occurred because the surface oxidation of metals and wear debris was weakened [3,21]. EDS analysis was performed to identify the chemical components on the surface of TBL and on the worn surface of wheel outside the TBL, as shown in Table 5. Only a few oxygen atoms were detected on the worn surface of wheel outside TBL, which means that it was rarely oxidized. However, the TBL was characterized by a higher oxygen content of 49.2 at $\%$, which means that the TBL contained iron oxides. Usually, the iron oxides at the wheel and rail interface under dry contact are $\mathrm{FeO}, \mathrm{Fe}_{3} \mathrm{O}_{4}$ and $\mathrm{Fe}_{2} \mathrm{O}_{3}$ [3]. The iron oxide type in wear debris formed at the wheel and rail interface under the low temperature condition $\left(-40{ }^{\circ} \mathrm{C}\right)$ was identified as a mixture of $\mathrm{Fe}$ and $\mathrm{Fe}_{2} \mathrm{O}_{3}$ through XRD in literature [19,21]. Meanwhile, a similar blackish phase at the low temperature $\left(-35^{\circ} \mathrm{C}\right)$ was confirmed as $\mathrm{Fe}_{2} \mathrm{O}_{3}$ via EDS [17]. In the present study, the atomic ratio of $\mathrm{Fe}$ and $\mathrm{O}$ was 4:5 which was larger than 2:3 (atom ratio of $\mathrm{Fe}$ and $\mathrm{O}$ of $\mathrm{Fe}_{2} \mathrm{O}_{3}$ ). Thus, the TBL was a mixture of $\mathrm{Fe}$ and $\mathrm{Fe}_{2} \mathrm{O}_{3}$. The decrease of COFs for test 5 and test 6 might then be attributed to the formation of TBLs on the wheel surface.

Even though the samples were ultrasonically cleaned in ethanol for $10 \mathrm{~min}$ or longer, a large area of wheel surface after testing at the low temperature was still covered by TBLs (Fig. 8(d)), which means that the adhesive strength between TBL and wheel surface at the low temperature was strong. Fig. 16 shows details of TBL on the wheel surface. It could be observed that TBL adhered to the sample surface closely and contained a large number of metal particles (bright spots). Meanwhile, some unbroken material was embedded in TBL. During sliding, the new surface of wheel substrate and new surfaces of metal particles were active. These surfaces were oxidized easily, leading to the formation of oxide film on particle surfaces and the wheel substrate surface. The oxide film on the particle surface hindered the formation of atomic bonding between particles $[36,37]$. At the low temperature (accompanied by low humidity), the oxide films on wheel substrate surface and particle surfaces were thinner than those formed at the room temperature. Consequently, the thinner oxide films were easier to be broken. After the oxide films were broken, the atomic bonding between particles were formed (it also happened between the particles and substrate surfaces). In this way, the atomic bonding provided a higher bonding strength than the shear strength between TBL and the counter surface. Thus, TBL was strongly adhered to wheel surface after testing in the low temperature environment.

\section{Conclusions}

Rolling-sliding wheel-rail wear tests were carried out at the room (around $20^{\circ} \mathrm{C}$ ) and low $\left(-40^{\circ} \mathrm{C}\right.$ ) temperatures with a hypereutectoid rail steel and two eutectoid rail steels. Based on results and analyses, the following facts can be concluded.

1. The material type had influence on the wear and damage of rails. The hypereutectoid rail had a lower mass loss and smaller crack lengths than eutectoid steels at the room temperature. At the low temperature, the hypereutectoid rail had a lower mass loss but large crack lengths than eutectoid steels.

2. The temperature had influence on the wear behaviors of wheel and rail materials. The mass losses of wheel and rail rollers were smaller at $-40{ }^{\circ} \mathrm{C}$ than at $20^{\circ} \mathrm{C}$. 
3. The temperature had influence on the damage behaviors of wheel and rail materials. At $20{ }^{\circ} \mathrm{C}$, the worn surfaces of rail and wheel rollers were dominated by surface cracks. However, at $-40{ }^{\circ} \mathrm{C}$, the worn surfaces of rail rollers were dominated by small cracks and oxidized spots whereas the worn surface of wheel rollers were dominated by surface cracks and TBLs. The crack lengths of eutectoid steels were smaller at $-40{ }^{\circ} \mathrm{C}$ than at $20{ }^{\circ} \mathrm{C}$; however, the cracks lengths of hypereutectoid rail were larger at $-40^{\circ} \mathrm{C}$ than at $20^{\circ} \mathrm{C}$.

\section{Declaration of competing interest}

The authors declare that they have no known competing financial interests or personal relationships that could have appeared to influence the work reported in this paper.

\section{Acknowledgments}

The work was supported by National Natural Science Foundation of China (Nos. 51775455 and 51975489), Sichuan Science and Technology Program (No. 2019YFH0094), China Postdoctoral Science Foundation (No. 2019M663548) and Fundamental Research Funds for the Central Universities (No. 2682020CX29).

\section{References}

[1] H. Chen, A. Namura, M. Ishida, T. Nakahara, Influence of axle load on wheel/rail adhesion under wet conditions in consideration of running speed and surface roughness, Wear 366-367 (2016) 303-309.

[2] W.J. Wang, R. Lewis, B. Yang, L.C. Guo, Q.Y. Liu, M.H. Zhu, Wear and damage transitions of wheel and rail materials under various contact conditions, Wear 362-363 (2016) 146-152.

[3] Y. Zhu, U. Olofsson, H. Chen, Friction between wheel and rail: a pin-on-disc study of environmental conditions and iron oxides, Tribol. Lett. 52 (2013) 327-339.

[4] N. Axén, S. Jacobson, S. Hogmark, Influence of hardness of the counterbody in three-body abrasive wear - an overlooked hardness effect, Tribol. Int. 27 (1994) 233-241.

[5] Y.H. Zhang, Q.Y. Zhou, Z.Y. Chen, F.S. Liu, Z.G. Zhou, Study on properties of rail U71Mn at low temperatures, J. China Railw. Soc. 27 (2005) 21-27.

[6] W. Brazil, A. White, M. Nogal, B. Caulfield, A.O. Connor, C. Mortonc, Weather and rail delays: analysis of metropolitan rail in Dublin, J. Transport Geogr. 59 (2017) 69-76.

[7] X.B. Li, The design of turnout snow-removing system for Harbin South Marshalling Yard, Railway Standard Design 59 (2015) 54-60.

[8] S. Dindar, S. Kaewunruen, M. An, J.M. Sussman, Bayesian Network-based probability analysis of train derailments caused by various extreme weather patterns on railway turnouts, Saf. Sci. 110 (2018) 20-30.

[9] X.M. Chen, T.L. He, S.Y. Liu, X.M. Zhang, Z.X. Ma, W.D. Wang, Research on track service state and maintenance responses of Harbin-Manzhouli railway, J. Railw. Sci. Eng. 12 (2015) 1304-1311.

[10] S. Grassie, P. Nilsson, K. Bjurstrom, A. Frick, L.G. Hansson, Alleviation of rolling contact fatigue on Sweden's heavy haul railway, Wear 235 (2002) 42-53.

[11] N. Saini, C. Pandey, M.M. Mahapatra, H.K. Narang, R.S. Mulik, P. Kumar, A comparative study of ductile-brittle transition behavior and fractography of P91 and P92 steel, Eng. Fail. Anal. 81 (2017) 245-253.

[12] Y.Q. Wang, W. Xi, Y.J. Shi, Experimental study of the impact toughness of rail steel at low temperatures, J. Tsinghua Univ. 47 (2007) 1414-1417.

[13] X.Y. Fang, Y.X. Zhao, H.W. Liu, Study on fatigue failure mechanism at various temperatures of a high-speed railway wheel steel, Mater. Sci. Eng. 696 (2017) 299-314.
[14] A.B. Yur'ev, L.A. Godik, N.A. Kozyrev, L.V. Korneva, A.V. Tokarev, Using Nitrovan alloy in the production of low-temperature rail steel, Steel Translat. 38 (2008) 756-758.

[15] C.J. Liu, Y.H. Huang, M.F. Jiang, Effects and mechanisms of Re on impacts toughness and fracture toughness of clean heavy rail steel, J. Iron Steel Res. 18 (2011) 52-58.

[16] I. Dey, S. Chandra, R. Saha, S.K. Ghosh, Effect of Nb micro-alloying on microstructure and properties of thermo-mechanically processed high carbon pearlitic steel, Mater. Char. 140 (2018) 45-54.

[17] Y. Lyu, E. Bergseth, U. Olofsson, Open system tribology and influence of weather condition, Sci. Rep. 6 (2016) 32455, https://doi.org/10.1038/srep32455.

[18] Y. Zhu, Y. Lyu, U. Olofsson, Mapping the friction between railway wheels and rails focusing on environmental conditions, Wear 324-325 (2015) 122-128.

[19] L. Ma, L.B. Shi, J. Guo, Q.Y. Liu, W.J. Wang, On the wear and damage characteristics of rail material under low temperature environment condition, Wear 394-395 (2018) 149-158.

[20] L. Ma, J. Guo, Q.Y. Liu, W.J. Wang, Fatigue crack growth and damage characteristics of high-speed rail at low ambient temperature, Eng. Fail. Anal. 82 (2017) 802-815.

[21] L.B. Shi, L. Ma, J. Guo, Q.Y. Liu, Z.R. Zhou, W.J. Wang, Influence of low temperature environment on the adhesion characteristics of wheel-rail contact, Tribol. Int. 127 (2018) 59-68.

[22] Y. Zhu, W.J. Wang, R. Lewis, W.Y. Yan, S.R. Lewis, H.H. Ding, A review on wear between railway wheels and rails under environmental conditions, J. Tribol. 141 (12) (2019), 120801.

[23] W.J. Wang, H.M. Guo, X. Du, J. Guo, Q.Y. Liu, M.H. Zhu, Investigation on the damage mechanism and prevention of heavy-haul railway rail, Eng. Fail. Anal. 35 (2013) 206-218.

[24] M. Masoumi, A. Sinatora, H. Goldenstein, Role of microstructure and crystallographic orientation in fatigue crack failure analysis of a heavy haul railway rail, Eng. Fail. Anal. 96 (2019) 320-329.

[25] R.O. Olivares, C.I. Garcia, A. DeArdo, S. Kalay, F.C.R. Hernández, Advanced metallurgical alloy design and thermomechanical processing for rails steels for North American heavy haul use, Wear 271 (2011) 364-373.

[26] Y.H. Zhang, C. Chuang, Q.Y. Zhou, Z.Y. Chen, F.S. Liu, M. Zhou, D.D. Liu, X.W. Liu, J.F. Guo, H.J. Wang, Test study on hypereutecoid rail for heavy haul railway in China, China Railw. Sci. 34 (2013) 1-7.

[27] U. Masaharu, U. Kouichi, Application of Hypereutectoid Steel to Heavy Haul Track Rail, Processings of the TMS Fall Meeting, Thermomechanical Processing and Mechanical Properties of Hypereutectoid Steels and Cast Irons, 1997. Warrendale (PA), USA.

[28] J. Takahashi, Y. Kobayashi, M. Ueda, T. Miyazaki, K. Kawakami, Nanoscale characterization of rolling contact wear surface of pearlitic steel, J. Mater. Sci. Technol. 29 (2013) 1212-1218.

[29] Q. Lai, R. Abrahams, W.Y. Yan, C. Qiu, P. Mutton, A. Paradowska, X.Y. Fang, M. Soodi, X.H. Wu, Effects of preheating and carbon dilution on material characteristics of laser cladded hypereutectoid rail steels, Mater. Sci. Eng. 712 (2018) 548-563.

[30] J. Ding, I.R. McColl, S.B. Leen, P.H. Shipway, A finite element based approach to simulating the effects of debris on fretting wear, Wear 263 (2007) 481-491.

[31] W.Y.H. Liew, Effect of relative humidity on the unlubricated wear of metals, Wear 260 (2006) 720-727.

[32] H. Kato, K. Komai, Tribofilm formation and mild wear by tribo-sintering of nanometer-sized oxide particles on rubbing steel surfaces, Wear 262 (2007) 36-41.

[33] G.Y. Deng, A.K. Tieu, H.J. Li, Z.M. Liu, X. Wang, H.T. Zhu, Thermo-mechanical coupled finite element analysis of rolling contact fatigue and wear properties of a rail steel under different slip ratios, Tribol. Int. 141 (2020) 105943.

[34] E.A. Gallardo-Hernandez, R. Lewis, R.S. Dwyer-Joyce, Temperature in a twin-disc wheel/rail contact simulation, Tribol. Int. 39 (2006) 1653-1663.

[35] J.F. Santa, P. Cuervo, P. Christoforou, M. Harmon, A. Beagles, A. Toro, R. Lewis, Twin disc assessment of wear regime transitions and rolling contact fatigue in R400HT-E8 pairs, Wear 432-433 (2019), 102916.

[36] M.X. Wu, Y. Yang, G. Yang, K.L. Huang, D.Q. Yin, Direct evidence for surface cleaning mechanism during field-activated sintering, J. Alloys Compd. 784 (2019) 975-979.

[37] C.S. Bonifacio, T.B. Holland, K.V. Benthem, Evidence of surface cleaning during electric field assisted sintering, Scripta Mater. 69 (2013) 769-772. 